
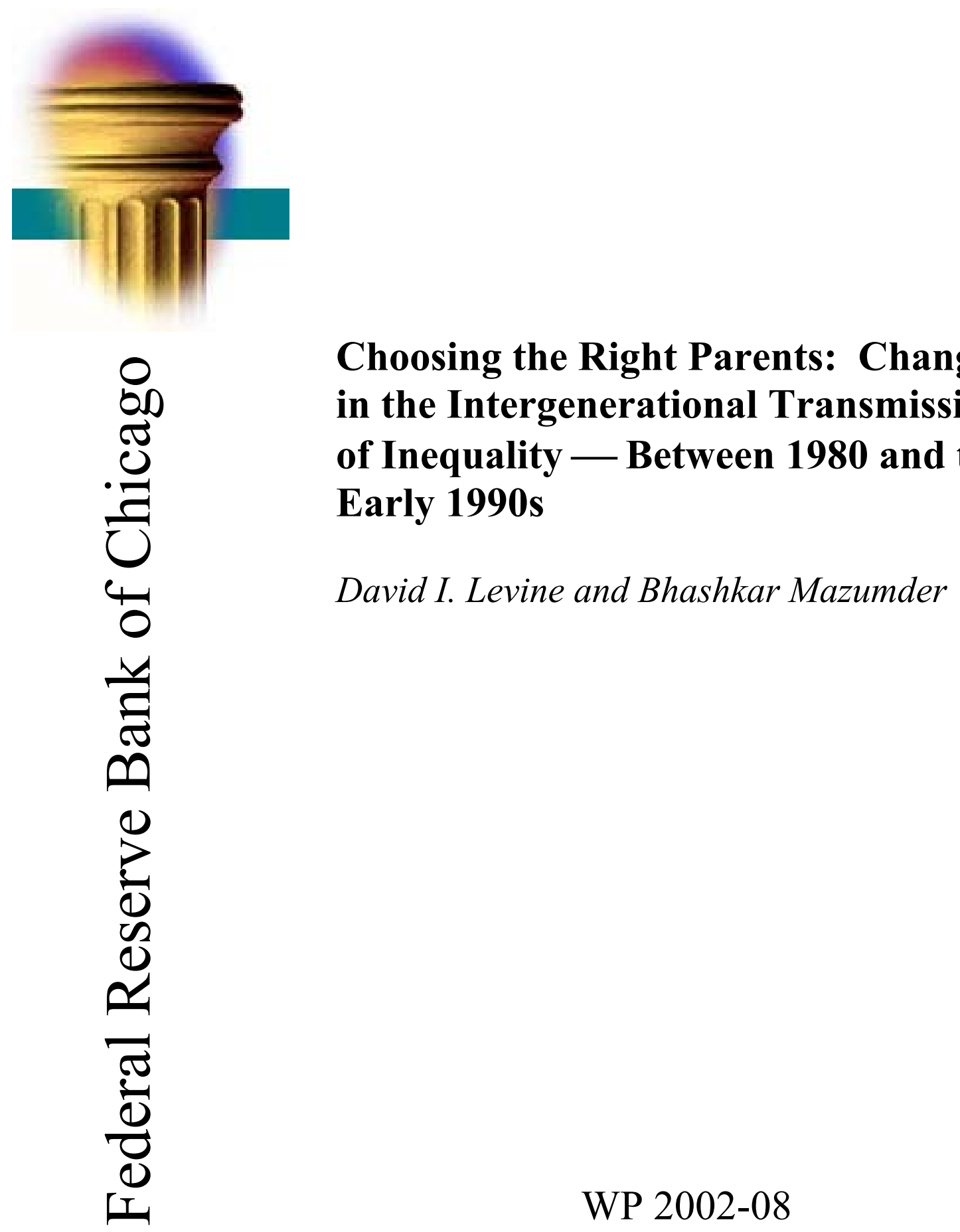


\title{
CHOOSING THE RIGHT PARENTS:
}

\section{CHANGES IN THE INTERGENERATIONAL TRANSMISSION OF INEQUALITY}

\section{BETWEEN 1980 AND THE EARLY 1990S}

\author{
DAVID I. LEVINE \\ Haas School of Business \\ University of California \\ BHASHKAR MAZUMDER \\ Federal Reserve Bank of Chicago
}

June 2002

Acknowledgements: We thank seminar participants at the Federal Reserve Bank of Chicago for useful comments. Funding from the Institute of Industrial Relations at the University of California, Berkeley, is gratefully acknowledged. Michael Reich suggested the topic and helped design an earlier version of the study. Mike Hanson, Susan Sassaloss, Ishak Saporta, and Chad Slawner provided research assistance on the earlier version. 
Abstract: This paper uses the National Longitudinal Surveys (NLS), the Panel Study of Income Dynamics (PSID), and the General Social Survey (GSS) to measure the elasticity of family income on men's adult earnings in 1980 and the early 1990s. The study finds a large and statistically significant increase in the importance of family income over time when comparing cohorts in the NLS, a dataset that has not been previously used for this purpose. We also find a large but statistically insignificant increase when using the GSS. The PSID, however, shows a large but statistically insignificant decline in this parameter. The results imply that changes in the effect of family income did not operate through the channel of human capital. Results suggest that the rate of inheritability of income may have increased in recent decades, but this evidence is not yet definitive. Researchers, therefore, should exercise caution when generalizing about trends over time when using small samples from just one dataset such as the PSID. 


\section{Introduction}

From the late 1970 s to the early 1990 s, cross-sectional income inequality among men in the United States increased dramatically (Levy and Murnane, 1992; Murphy and Welch, 1992). This increase occurred across almost all dimensions: age groups, industries, occupations, racial groups, educational groups, and residual inequality holding constant those factors. Researchers have attempted to decompose the rise in inequality across many dimensions but, for the most part, have not analyzed possible changes in the importance of an individual's family background.

This is an important omission considering that a growing literature has documented that the intergenerational transmission of economic status is quite substantial (Solon, 1992; Zimmerman, 1992; Mulligan, 1997). These studies suggest that the circumstances in which children grow up have a powerful long-term influence on their earnings as adults. This literature, however, has largely focused on specific cohorts of children at a particular point in time and has not examined changes in intergenerational linkages over time.

This paper attempts to fill this void by examining the effect of family income on the adult earnings of sons at two different points in time using three different datasets. In particular, we use two cohorts from the National Longitudinal Surveys of Labor Market Experience (NLS), a dataset that despite having the largest samples has not yet been used to address this question. We also use the Panel Study of Income Dynamics (PSID) and the General Social Surveys (GSS) to check the robustness of the results. The time periods chosen are 1980 and the early 1990s, a period during which cross-sectional inequality grew markedly and the returns to skills appear to have increased. Therefore, one might also expect to observe a rise in the "return" to having better-off parents.

We also decompose changes in the intergenerational elasticity of income into the elements that do and do not operate through the channel of sons' education. This decomposition is useful in understanding intergenerational inequality and policies that might address this issue. Because the economy has experienced a rise in the return to education over the time period studied, the effect of parental income on 
sons' income will rise even if the effect of parental income on sons' education remains constant over time. In this case, the rising inheritance of economic status will be due solely to a rise in the return to education and not, for example, to an increase in the ability of better-off families to provide greater educational opportunity for their children.

\section{Theory and Literature Review}

As the saying goes, "The most important decision you will ever make is choosing the right parents." In fact, a number of studies have found that parents' characteristics help predict a child's lifetime success (e.g., Atkinson, 1981; Massagli and Hauser, 1983). Many studies (but not all) also find that family income is particularly important (Corcoran et al., 1992; Duncan and Brooks-Gunn, 1997; contra see Mayer, 1997; Shea, 2000).

What is less clear, however, is exactly how the intergenerational transmission of income works: Is it comprised of a genetically transmitted ability; parents' investment in their child's human capital, the implicit or explicit transmission of valuable social networks and social capital, or the high propensity of sons to have the same occupation as fathers? Data limitations, overlapping definitions of what is included in each channel, and interactions among the channels make it extremely difficult to unravel the relative importance of these factors (Solon, 1999, and Bowles and Gintis, 2001). As a first step, in this study we decompose the overall effect of family income in both time periods into two parts: an effect that operates through the channel of sons' education and a separate effect that is independent of sons' education.

\section{Past results on the intergenerational transmission of economic status}

Social scientists have long been interested in the intergenerational transmission of inequality. They have largely focused on three measures of parental economic standing: educational attainment, 
income, and occupational status. ${ }^{1}$ Although economists tend to focus on income, all three of these measures are useful in measuring parents' lifetime economic status (Goldberger, 1989).

The early studies in the literature found the intergenerational correlation of income was lower than the intergenerational correlations of education or occupational status. A problem with these studies, however, is that they used only a single year of measured income for both fathers and sons. Due to measurement error and transitory fluctuations, a single year of income is a poor proxy for lifetime economic status and will result in coefficients that are severely biased downward (Bowles, 1972; Solon, 1989, 1992). Moreover, these studies' use of nonrepresentative samples often led to attenuation bias due to limited variation in parental income. ${ }^{2}$

In fact, during the 1990s, several empirical studies (Solon, 1992; Zimmerman, 1992) using nationally representative longitudinal studies estimated substantially higher intergenerational elasticities in income. These studies averaged fathers' income over several years and eliminated much of the noise that would otherwise result in biased regression coefficients. The consensus view of the intergenerational elasticity in earnings is about 0.4 (Solon, 1999). ${ }^{3}$

A number of social scientists have investigated changes over time in the intergenerational transmission of education, income, and occupational status up through the 1970s. In general, links between generations became weaker from the 1950s to the 1970s (e.g., Hauser and Featherman, 1977). Since 1970, the results on changes in correlations of occupation, education, and income are less consistent. Hout (1988) has found that the intergenerational transmission of occupational status continued to weaken at least through the late 1980s. Gottschalk et al. (1994) summarize several studies,

\footnotetext{
${ }^{1}$ Other important family characteristics include wealth (studied by Menchik, 1979) and consumption (studied by Mulligan, 1997). Lack of appropriate data preclude the study of how these intergenerational correlations have changed over time.

${ }^{2}$ For example, Behrman and Taubman (1985) used a sample of white male twins who served in the armed forces. Sewell and Hauser (1975) used a sample of high school seniors in Wisconsin who were no longer in school seven years later.

${ }^{3}$ As a result of attrition and small sample size, however, these more recent studies still used relatively short-term averages of income as a proxy for lifetime economic status. Using a new dataset that contains the long-term earnings histories of fathers, Mazumder (2001) has estimated that the intergenerational elasticity in earnings may actually be close to 0.6 .
} 
each of which examined data from different decades. To the extent that the results in the studies are comparable, these comparisons also imply a decline in occupational status inheritance.

Based in large part on the studies of declining occupational correlations, McMurrer and his coauthors (1997) conclude, "Overall, the evidence suggests that the playing field is becoming more level in the United States. Socioeconomic origins today are less important than they used to be." The results are less clear for education and income than for occupation.

Turning first to education, there is some evidence of a rise in the transmission of educational attainment across generations but the evidence is not conclusive. David Ellwood and Thomas Kane (1999) find that in the 1990s compared with the 1970s, the proportion of dependent 18- and 19-year-olds enrolled in college rose for children of the richest income quartile, but declined slightly for children of the poorest quartile. Similarly, Manski (1993) finds that the correlation of parental income and youths' college enrollment rose using Current Population Survey data from 1970 to 1988 . In contrast, he finds that the correlation between income quintile and college graduation rates of the high school classes of 1972 and 1980 were similar. (The analysis of college graduation rate compared the NLS of the class of 1972 and the High School and Beyond survey of the class of 1980).

Changes in the intergenerational transmission of income also have mixed results. Fertig (2001) uses the PSID and constructs five overlapping cohorts of parents and children. She finds a statistically significant decrease in the intergenerational elasticity of earnings over time between fathers and sons, but little change for other pairs of parents and children. In each of her constructed cohorts, Fertig uses a fiveyear average of children's earnings between the ages of 21 and 40 . Under this design, individuals born over a twenty-year period are all part of the same "cohort," and there is significant overlap across her five cohorts.

Mayer and Lopoo (2001) also use the PSID but measure the elasticity of family income on sons' family income and sons' wages. In contrast to Fertig, they hold sons' age constant at 30, pool cohorts of sons born between 1949 and 1965, and estimate a linear time trend in the intergenerational elasticity. 
They find a negative but statistically insignificant decline in this parameter. When the sample is restricted to those born after 1952, however, the decline does become statistically significant.

Hauser (1998) uses the GSS from 1972 and 1996, and finds no change in the correlation between fathers' economic status and sons' economic status. His procedure uses occupation to infer economic status by matching Census occupation codes to measures of income and education. ${ }^{4}$ The measures are the percentage of occupational incumbents that received a certain level of income and the percentage that completed a year of college.

Given the mixed findings from past studies and the various methodological techniques that have been used, it is important to analyze several datasets using one consistent approach. This paper builds on these past studies on the intergenerational transmission of income by examining a dataset that has not yet been used for this purpose, the NLS.

The NLS has at least one clear advantage over the PSID and the other datasets: It has a very large longitudinal sample of specific cohorts of young men at two different points in time. We can therefore anticipate that results from the NLS are more likely to produce a statistically significant change in the intergenerational transmission of economic status than do the other datasets used. We can also apply virtually the same methodology on two other datasets, the PSID and the GSS, to check the robustness of the results. Finally, rather than simply documenting the change in the intergenerational transmission, we decompose the change into two parts, a portion that is related to sons' education and a part that is unrelated to sons' education.

\section{Methods}

We follow the standard approach used in the previous literature that measures the intergenerational elasticity by running the following regression:

$$
y_{s}=\rho^{*} y_{f}+w .
$$

\footnotetext{
${ }^{4}$ Hauser also uses the same technique with the 1962 and 1973 Occupational Change in a Generation Surveys (OCG) and the 1986-1988 Survey of Income and Program Participation (SIPP). However, the results with the OCG cover changes during an earlier time period than what is examined here. The results from the SIPP provide results only at a single point in time.
} 
Here $y_{s}$ represents the log earnings of the son as an adult and $y_{f}$ represents his family's income during adolescence. ${ }^{5}$ To minimize attenuation bias, $y_{f}$ is averaged over three years. The disturbance term $w$ captures any random noise in sons' log earnings such as measurement error.

The coefficient of interest is $\rho^{*}$, which measures the intergenerational elasticity. ${ }^{6}$ The intergenerational elasticity is not necessarily causal but is an important descriptive parameter that captures all possible influences on sons' earnings that are correlated with family income. An intergenerational elasticity of 1 would imply an extremely rigid society where the son's position in the earnings distribution would typically replicate his family's position in the income distribution. In contrast, an intergenerational elasticity of 0 suggests an extremely mobile society in which the son's earnings are unrelated to family income. Therefore, a society with a high $\rho *$ is a less mobile society than one with a low $\rho *$.

To decompose the intergenerational elasticity further, we propose the following framework in which equation (1) is the reduced form in a somewhat more complicated system. We start by viewing the son's earnings as a function of the son's own education $\left(e_{s}\right)$, parent's education $\left(e_{p}\right)$, as well as family income: ${ }^{7}$

$$
y_{s}=\beta e_{s}+\gamma e_{f}+\rho y_{f}+\varepsilon .
$$

Here, $\beta$ is the return to son's own education and $\gamma$ is the return to parent's education after controlling for family income. Similarly, $\rho$ is the return to family income controlling for both the human capital of sons and parents. In this setup, if one runs the regression shown in (1), the estimate for $\rho^{*}$ will capture not only the direct effects of family income ( $\rho$ ) but will also pick up some portion of the effect of the son's own education and the parent's education on son's earnings ( $\beta$ and $\gamma)$.

\footnotetext{
${ }^{5}$ Sons' earnings are age adjusted by regressing sons' earnings on a quadratic in age. Family income is similarly regression adjusted by using the age of the father. Intercept terms are omitted in all equations for simplicity. ${ }^{6}$ This is similar to but not equal to the intergenerational correlation that has been emphasized in the sociology literature on intergenerational mobility. One advantage of the intergenerational elasticity is that it is not biased by mismeasurement of the sons' earnings and therefore does not require a multiyear average.

${ }^{7}$ Parent's education is the sum of father's and mother's education.
} 
We next assume that the son's education depends on the income and education of the parents:

$$
e_{s}=\tau e_{f}+\lambda y_{f}+u
$$

Finally, to complete the decomposition, we have the following noncausal auxiliary equations for the education levels for the sons and for the parents: ${ }^{8}$

$$
e_{f}=\theta y_{f}+z
$$

In (3), the son's education is a function of both family income and the parent's education, and in (4), parent's education is a function of family income. Given (2), (3), and (4), the coefficient from running the regression in (1) can be decomposed as follows:

$$
\operatorname{plim} \rho^{*}=\rho+\gamma \theta+\beta[\lambda+\theta \tau] .
$$

Therefore, if we run all of the regressions in equations (1) to (4), we can break down the overall intergenerational elasticity, $\rho^{*}$, into two components. The first two terms, $\rho+\gamma \theta$, constitute the "direct" effect of family income, which is unrelated to the son's education, while the remainder of the expression, $\beta[\lambda+\theta \tau]$ is the part of the intergenerational elasticity that operates through the channel of the son's observable human capital. Part of the direct effect, $\gamma \theta$, represents that portion of the direct effect of parent education on sons' income that is correlated with family income. Because parent education is likely to have little direct effect on the son's income after controlling for the son's own education, we might expect this term to be quite small, and therefore much of the direct effect is likely to be captured by $\rho$. The goal of this paper is to run these regressions for two time periods and then observe both the overall change in $\rho^{*}$ and the key contributing factors to this change.

\section{Data}

\footnotetext{
${ }^{8}$ It should be emphasized that the parameter estimates in these equations are not intended to uncover causal processes. For example, the causality almost surely runs primarily from fathers' education to their incomes, not as we have written equation (4). These equations are useful, however, as an accounting framework for identifying
} 
We analyze two cohorts from the NLS as well as two cohorts that are similarly constructed from the PSID. We also select two samples from the GSS that are comparable to the cohorts that are used with the longitudinal datasets.

\section{NLS}

The NLS, sponsored by the Bureau of Labor Statistics, includes several age cohorts and covers several periods from 1966 through 2000 (U.S. Department of Labor, 2001). We examine the Young Men cohort, surveyed initially in 1966 and then nearly every year until 1981. We pair this group of young men with a similar male subsample of the later National Longitudinal Survey of Youth (NLSY), begun in 1979 and continued through 2000, to examine the intergenerational transmission of income for two different time periods. Both samples include an oversample of blacks.

The two snapshots of sons' earnings were taken in 1980 and 1993. These dates were 14 years from the survey start dates for the NLS Young Men cohort (for our purposes, NLS66), and the NLSY Young Men (NLSY79) cohort, respectively. The surveys began when the respondents were ages 14-24 and 14-22, respectively. For our analysis of outcomes 14 years hence, we include adult male respondents ages $28-36 .{ }^{9}$ We take data on family income over a three-year period covering 1966 to1968 for the NLS66 cohort and 1978 to 1980 for the NLSY79 cohort. $^{10}$

The sample is restricted in the later period of each survey to male respondents who were not living with their parents, were not enrolled in school, and provided data on their current earnings and years of schooling. In addition, the sample is restricted to families where the son lived with both parents and where both parents provided their years of schooling. Family income must have been positive in all three years. We analyze the effects of the sample-selection rules and test the sensitivity of the results to

sources of change in $\rho^{*}$ related to sons' observed human capital. Any changes in these parameters could be due to time-varying unobservable factors.

${ }^{9}$ In order to maintain consistency between the NLS66 and NLSY79, we drop those over the age of 22 in the beginning of the NLS66. This also helps ensure that our samples do not overrepresent sons who remained at home at a late age.

${ }^{10}$ For the NLSY79 cohort, measures of income come from the surveys conducted in the subsequent year. 
these restrictions later. Despite these restrictions, the sample size for the NLS66 cohort is 868 and for the NLSY79 is 1092 . This is significantly larger than the samples used in previous studies that relied on the PSID, the dataset we turn to next. ${ }^{11}$

\section{The PSID}

The PSID, begun in 1968, is a longitudinal study of a representative sample of U.S. individuals and their families. The study is conducted at the Survey Research Center, Institute for Social Research, University of Michigan (Institute for Social Research, 2000). The analysis samples consist of males ages 28-36 in 1980 or 1992 who were the head of the household, were not living with their parents, were not enrolled in school, and provided data on their income and schooling. ${ }^{12}$ We include the oversample of poorer families who were part of the Survey of Economic Opportunity (SEO) to remain consistent with the NLS. Information on family background comes from interviews of the parents in 1968-1970 and 1979-1981. As with the NLS, both parents must have provided information on years of schooling and families must have positive income in all three years.

\section{General Social Survey}

The GSS, conducted by the National Opinion Research Center (NORC) is an annual (biannual beginning in 1994) cross-sectional survey of a representative sample of the entire U.S. population. We have chosen a subsample of males ages 28-36 to parallel the samples used in the NLS and the PSID. Because the annual sample size for the GSS is roughly 1,500 for respondents of all ages, we have pooled the years 1976-1984 to correspond with the 1980 period and the years 1989-1994 to correspond with the early 1990s as in the other datasets. ${ }^{13}$ Because the GSS is a cross-sectional survey, family background data have been gathered during each administration of the survey. The GSS sample is also restricted to

\footnotetext{
${ }^{11}$ For example, Solon (1992) has samples of 301 to 309 when he averages fathers' income over three years.

12 Sons' earnings are measured in 1992 because that is the last year in which there is final data that has been fully processed by the Survey Research Center.
} 
respondents that were not living with their parents, were not enrolled in school, and provided data on their income and schooling. ${ }^{14}$ As with the other surveys, we require that years of education were provided for both parents.

\section{Comparing the Datasets}

We have made our datasets as comparable as possible. We have examined men ages 28-36 who grew up with two parents (defined here as a mother or stepmother, plus a father or stepfather) present during their youth (at age 14-22 for NLS and PSID respondents, or age 16 for GSS respondents). The lower bound on age is set at 28 so that most respondents would have finished their education. The upper bound of 36 allows us to maximize the sample size with the NLS cohorts. Summary statistics are presented in Table 1.

Although similar along most measures, each dataset contains distinctive features. The cohorts of sons used for analysis differ slightly between the NLS and PSID for the early period. The NLS66 uses men born between 1944 and 1952, while the PSID uses men born between 1946 and $1954 .{ }^{15}$ The pooling of years in the GSS results in using men who were born anytime from 1940 to 1956. For the later period, both the NLS and PSID use men born between 1957 and 1965 while the GSS uses men born between 1951 and 1966. The surveys also differ in the timing of when parental data were collected. For the older cohort, the NLS66 uses data on family income for the years 1966-1968, compared to 1967 through 1969 for the PSID. The GSS uses information about family income when the son was 16 years old.

There are also differences in the reporting of data across the datasets. In the NLS66, measures of family income and parent education are gathered from the sons when they were ages $14-25 .{ }^{16}$ In contrast,

\footnotetext{
${ }^{13}$ The latter period only uses a five-year range because the question regarding relative family income was eliminated starting with the 1996 survey.

${ }^{14}$ In the samples that use occupation and industry to determine fathers' income, these variables must be nonmissing.

${ }^{15}$ We show later that the results are not changed if we use the same cohort in both datasets.

${ }^{16}$ Family income is collected for the first three years of the sample so sons may be as old as 25 when this information is reported.

close up
} 
for the NLSY79, family income is provided directly by the parents. ${ }^{17}$ In the absence of any correction, the change in the estimates of the intergenerational elasticity over the two cohorts would likely be biased due to differing degrees of measurement error. Fortunately, income measures are provided by fathers in a subset of the NLS66 because they were part of the NLS older men's' cohort. We make use of the dual measures of family income for this subset of the sample to adjust our estimates appropriately. In both NLS cohorts, data on sons' earnings and education are self-reported during their adult years.

In the PSID, data on family income and parent education comes directly from the parent questionnaires for both cohorts. In the GSS, all data are obtained from the respondent during the single interview of the respondent as an adult. Respondents answer retrospectively about their parents and their family income at age 16. Therefore, bias in the GSS might be particularly large due to the likelihood of poor recall.

There are also differences in the sample characteristics across the datasets. The NLS oversamples blacks in both cohorts. The PSID oversamples poorer households. The GSS, however, is a nationally representative sample in each year. Both the NLS and PSID are longitudinal datasets and are subject to attrition. Sample weights, therefore, are used in all of the estimations with the NLS and PSID to address issues of representativeness. Separate analyses also have been conducted on white and black subsamples to check the robustness of the results.

\section{The Measures}

For the NLS samples, we average family income over the first three years of the survey. All measures of family income and sons' earnings are converted (using the CPI-U-X1) to 1966 dollars in the NLS66 and 1979 dollars in the NLSY79. Maternal and paternal years of education are drawn from the first year of the survey. In the NLS66, sons' education is taken from the 1976 survey (when sons were between the ages of 24 and 32), while in the NLSY79, responses are measured contemporaneously with

\footnotetext{
${ }^{17}$ Family income data was provided by parents in cases where the respondents were still living with their parents which is the case with our sample (conversation with CHRR staff).
} 
earnings in 1993. The available education measures are top coded at 18 years in the NLS66 and at 20 years in the NLSY79. To maintain comparability, education is censored at 18 years in the NLSY79. In the NLS66, family income is coded categorically, while in the NLSY79 it is continuous. To create an NLSY79 variable with the same characteristics as its NLS66 counterpart, we have adjusted the category boundaries for the NLS66 measure by inflation (using the CPI-U-X1) and recoded the NLSY79 family income using these new categories. A small number of responses have been top-coded.

Interval measures of income have been coded at the midpoint of the interval, and natural logs have been taken of the midpoints to measure log (income). The top-code for each variable is set at 1.5 times the truncation level. Different treatments of the top-coding do not change the results.

In the PSID, family income is measured continuously. As with the NLS, the CPI is used to deflate all income measures to either 1967 or 1978 dollars depending on the sample cohort. Parent education measures are taken from the 1968 or 1979 surveys, while sons' education is measured contemporaneously with earnings in either 1980 or 1992. Parents' education goes up to 24 years in the 1968 survey. In the 1979 survey, parent education is top-coded at 17 years, but information on whether the parent completed a graduate degree is available. We impute the years of education for parents with a graduate degree in 1979 at 20 years. No adjustment is made for top-coding of income variables.

The GSS has a coarser family income measure. Respondents are asked how they would compare their family's income when the respondent was 16 years old relative to the average American family. The responses are categorized on a 1 to 5 scale (e.g., 1 = "far below average," 3 = "average," 5 = "far above average"). Although this subjective categorization is a very blunt measure of family income, it might actually serve as a somewhat better measure of permanent economic status than does using just a single year of actual income. Using this categorical measure of relative family income, we impute a dollar value of family income based on historical Census data on percentiles of the distribution of family income for the years in which the sons were age $16 .{ }^{18}$ Specifically, we use the 20th, 40th, 50th, 60th and 80th

\footnotetext{
${ }^{18}$ The data is drawn from publicly available historical tables of family and household income produced by the Census Bureau.
} 
percentiles to match the subjective responses. ${ }^{19}$ Since far fewer than $20 \%$ of respondents actually chose extreme values such as 1 or 5, we also experimented with using percentiles of the distribution that roughly correspond to the cumulative distribution of the relative family income variable and discuss these results as well. $^{20}$

In a separate analysis, we also use the sons' report of their fathers' occupation, industry, and class of worker status along with information on the region in which the son lived at age 16 to construct a second measure of parents' economic status. Specifically, we use microdata samples from the 1960, 1970, and 1980 decennial censuses to calculate the mean annual earnings of fathers based on cells constructed from these four variables. ${ }^{21}$ We determine the year in which the son was age 16 and use the closest decennial census year to impute the earnings of the fathers.

The measure for sons' earnings in the GSS is categorical. Respondents mark one of approximately 20 categories (\$10-12,000, for example). The precise number of categories depends on the year, and the maximum category changes over time to approximately track inflation. Midpoints of the intervals are used to create the continuous measure used in the analysis. The CPI is used to convert all income measures to 1997 dollars. All education measures in the GSS are top-coded at 20 years.

\footnotetext{
${ }^{19}$ Ideally, we would have chosen the midpoints of the quintiles of the distribution to match the five categorical responses, but data on many of these percentiles are not publicly available for the years we are interested in. In addition, we are not aware of micro samples that would allow for such calculations before the late 1960s, which is necessary for our older cohort. In addition, it would be preferable to use percentiles of the distribution of permanent income, but such data is not available.

${ }^{20}$ These are the 10th, 20th, 50th, 90th and 95th percentiles. The 10th and 90th percentiles for family income are not available but are based on calculations by the authors using information on these percentiles of household income that are available from 1967. Please contact the authors for more detail on how the percentile measures are calculated.

${ }^{21}$ We use the Integrated Public Use Microdata Series (IPUMS-98) datafiles produced by the University of Minnesota's Minnesota Population Center (MPC). Specifically, we use the 1960 "general" file, the 1970 "Form 2 State" file, and the 1980 " $1 \%$ Metro" file. If a match between the GSS and IPUMS can not be made when using all four variables, we construct cells using progressively fewer variables until all fathers can be successfully matched. Sons in the older cohort who were surveyed between 1976 and 1984 are coded in the GSS using the 1970 Cenus occupation and industry codes. These codes are converted to 1960 codes when necessary using the IPUMS 1950 codes, which were produced for each decenial census to standardize occupation and industry codes over all censuses. Similarly, all of the sons interviewed between 1989 and 1994 are coded using the 1980 Census codes. When necessary, these codes are translated to the 1970 codes using the IPUMS' 1950 codes.
} 


\section{Results}

In Table 2, we present the results of the estimation of equations (1) through (4) for two time periods for all three datasets.

\section{The reduced form}

The reduced form estimates of equation (1) produce the standard intergenerational elasticity that has been typically measured in previous studies. We show the results for both time periods using the NLS in the top panel of Table 2. For the older cohort covered by the NLS66, the estimate of the intergenerational elasticity is 0.217 . Although this is substantially below the consensus estimate of 0.4 discussed earlier, it is not very different from most previous results using the same data. ${ }^{22}$ The result for the NLSY79 sample, however, is nearly double that found for the NLS66 at 0.414 . Moreover, the difference in the point estimates is statistically significant at less than the 1 percent level.

As noted earlier, however, the NLS66 sample uses sons' report of their family income rather than parents' self-report. To correct for this problem, we rerun the regression for the NLS66 using a correction for errors-in-variables that uses the reliability ratio to rescale the coefficient estimate. We use a subsample of the NLS66, in which fathers also reported family income, to obtain an estimate of the reliability ratio of using sons' report as a proxy for parent-reported income. We code fathers' reported family income in exactly the same way as sons' report of family income, and use a subsample of fatherson pairs where information on both measures of income are available for all three years. ${ }^{23}$ The estimated

\footnotetext{
${ }^{22}$ Peters (1992) obtain 0.24 when using up to five-year averages of family income for both parents and sons. Altonji and Dunn (1991) estimate an elasticity of 0.27 when using up to seven years of fathers' family income and up to 8 years for sons' family income. Osbourne (2001) obtains an estimate of 0.249 when using three-year averages of fathers' earnings. Zimmerman (1992), in contrast, using much more restrictive sample-selection rules on earnings and labor force status, estimates an elasticity of 0.54 using five-year averages of fathers' earnings and a single year of earnings for sons'. All of these studies use sons who were matched to fathers contained in the older men's cohort. Using such a restriction dramatically lowers the sample size and introduces possible age-related bias because the fathers are older than average. In this study, using this subsample actually lowers the elasticity estimates even further.

${ }^{23}$ Specifically, we regress the log of the three-year average of fathers' reported family income on the analogous measure reported by the sons. Under the assumptions of classical measurement error, the resulting coefficient is the equivalent of the reliability ratio of using the son's report as a proxy for the father's report.
} 
reliability ratio is 0.93 . The corrected coefficient estimate for the NLS66 is only slightly higher at 0.235 . The increase in the elasticity over time, however, remains statistically significant even after making this adjustment.

In the PSID, the point estimate for the early period is 0.452 and for the later period is 0.288 (panel B). The decline of 0.164 is large, but it is significant only at the 18 percent level. This general decline is consistent with the results found in Fertig (2001) and Mayer and Lopoo (2001), who also use the PSID.

Finally, when using the relative family income variable with the GSS (Panel C), the point estimate rises sharply from 0.126 in the early period to 0.513 in the later period. The point estimate for the early period, however, is not statistically significant at any meaningful level, and the standard errors are high in both periods compared to the other datasets. Still the change in the coefficients is very large and is significant at the 8 percent level, suggestive of a rise in the intergenerational elasticity.

When we use the alternate percentile measures that recode income classes with data from the relevant points in the extreme tails of the income distribution, we find that the elasticity rises from 0.142 in the early period to 0.216 in the later period (not shown). Using this measure, the point estimates are now statistically significant, but the change in coefficients is not. ${ }^{24}$ Given the rough measure of family income, it is not surprising that the coefficients are generally lower than those presented using the other datasets due to greater measurement error.

Finally, we use the GSS to estimate the elasticity in both periods using each father's income derived from his occupation, industry, class of worker status, and region of residence (Panel D). Using this variable, the elasticity rises only slightly from 0.178 to 0.192 and the change is far from statistically significant. This result is similar to the findings of Hauser (1998) who uses a similar approach to measuring changes in the intergenerational transmission of economic status with the GSS.

Given the different findings in the three datasets, how can the results be reconciled? From a statistical point of view, each dataset may be viewed as a draw from the population with a certain amount

\footnotetext{
${ }^{24}$ We do not highlight these results in the table because we believe that the data drawn from the extreme tails of the distribution are likely to be subject to greater mean-reverting transitory fluctuations.
} 
of sampling error. Of the three datasets, only the NLS samples are large enough to reliably detect even quite large changes in the intergenerational elasticity. At the same time, the finding of a decline in the PSID raises concerns about the robustness of the NLS results and suggests that the finding of an increase in the inheritability of income should not be overstated. The results from the GSS are broadly consistent with the NLS findings; at the same time, the GSS has the most measurement problems.

One criticism that could be made is that our simple errors-in-variables procedure does not adequately correct for differences in the quality of the reporting of family income across the NLS cohorts, and, therefore, the results of the change from the NLS may still be biased upwards. In response, we appeal to the findings from Altonji and Dunn (1991), Peters (1992), and Osbourne (2001) who find similar results with the NLS66 even though they use parent-reported family income. In addition, our estimate for the later period using the NLSY79 does not suffer from any measurement error relative to the PSID but still shows a sharply higher estimate of 0.414 compared to 0.288 from the PSID. At a minimum, then, our findings are still important as a cautionary flag for studies that rely solely on the PSID and argue that intergenerational mobility has increased.

A second potential problem is that there might be changes over time in the transitory share of the overall earnings variance. This would influence the degree to which mismeasurement of permanent income due to transitory noise might be influencing the results differently in the two time periods. A common view might be that due to rising rates of job displacement and the decline of career-long jobs, the transitory variance might be rising relative to the overall variance of earnings. If this were the case, however, then it would only strengthen our finding, since it would imply less accurate measurement of permanent income in the later period and a more attenuated estimate of the intergenerational elasticity. Evidence from Gottschalk and Moffitt (1994) shows that the permanent and transitory component increased roughly proportionately from the 1970 s to the 1980 s so that the fraction of the total variance accounted for by each component stayed roughly the same. Also, by using three-year averages of family income, we should have removed a large amount of this noise in both time periods. 


\section{Decomposing the changes}

The results from the other regressions in Table 2 decompose the intergenerational elasticity. Using the NLS, the effect of family income conditional on sons' own education and parents' education (equation 2) rises sharply over time from 0.137 to 0.319 , and the change is statistically significant. In the PSID, we find the reverse result as the coefficient falls from 0.319 to 0.034 . In this case, the decline is statistically significant in the PSID. In the GSS, when using relative family income, the effect of family income conditional on own and parent education is actually negative in the early period $(-0.127)$ but rises sharply over time. The change, however, is not significant. When using fathers' income based on industry and occupation, the "conditional" intergenerational elasticity is close to zero and insignificant in both periods.

The return to sons' own education rises from around 5 percent to between 9 and 10 percent in both the NLS and GSS. This increase is roughly in line with what others have found with the Current Population Survey and other datasets. In the PSID, the return to education is somewhat higher in the earlier period at 7.6 percent but does not rise by a statistically significant amount in the latter period (to 9.8 percent). The surprisingly small and insignificant increase in returns to education in the PSID is also present if we do not condition on family characteristics (results not shown). This surprising result reduces our confidence in other findings with the PSID.

Interestingly, parents' education conditional on sons' own education and family income usually does not help predict sons' income. The one exception among the six estimates of this parameter is in the PSID during the later period.

The results for family income conditional on observable human capital, therefore, appear to follow the same pattern across datasets as do the results for the unconditional effect of family income. We are suspicious of the PSID results indicating that family income has essentially no independent effect on sons' earnings during the later period.

It is possible that the poor measurement of family income might be a factor, although we have no direct evidence on this point. If parent education is acting as a proxy for an otherwise poorly measured 
family income variable and picking up a large part of the correlation between family income and sons' earnings, such measurement error would explain why parents' education only appears to be a predictor of sons' earnings in the later period in the PSID.

The results relating sons' education to parental characteristics (equation 3) are of independent interest. The effect of family income on sons' years of education appears to have declined in the NLS and the PSID. In contrast, the effect of parents' education on sons' education has increased in both of these datasets. None of these changes, however, are significant at the 5 percent level. These results are mixed in the GSS. When fathers' income is measured based on industry and occupation, the results are similar to those found in the other datasets. However, when the GSS uses the relative family income variable, the results are reversed. Given the high correlation between true family income and parents' education, we do not give much weight to the results for equation 3 in the GSS.

These results provide some suggestive evidence that liquidity constraints may have become less binding over time with respect to financing sons' schooling. At the same time, the fact that parents' education level may be more strongly tied to sons' education suggests that family background continues to strongly influence educational attainment.

We now discuss the decomposition of the overall change in the intergenerational elasticity. Virtually the entire change in the NLS is accounted for by the change in the direct effect -- that is, the effect of family income conditional on sons' own education and parent education. ${ }^{25}$ Only about 6 percent of the increase in the intergenerational elasticity is due to increases in the transmission of years of schooling or increases in the return to schooling. In the PSID, more than 100 percent of the estimated decline in the intergenerational elasticity is reflected in the direct effect. The increase in the returns to schooling contributes a small positive amount to the change in the intergenerational elasticity. Therefore, although the two datasets have vastly different conclusions about the direction of the change in intergenerational mobility, neither points to changes in the transmission of education as playing an

\footnotetext{
${ }^{25}$ As we discuss in the Methods section, the direct effect also includes the portion of the effect of parents' education on sons' income that is correlated with family income.
} 
especially large role. Finally, in the GSS, about two-thirds of the estimated increase in the intergenerational elasticity is due to the change in the direct effect when using the relative family income variable.

\section{Sensitivity Analyses}

We have conducted a wide range of tests to ensure that our sample-selection rules do not affect the results. In our comparisons of the NLS and PSID, we use identical cohorts in the later period (19571965) and we use slightly different cohorts in the early period (1944-1952 for NLS compared to 19461954 for PSID). Restricting the samples for the early period in both datasets to those born between 1946 and 1952 has little effect on the results.

Although requiring three years of positive family income eliminates a large degree of measurement error, it also might make the sample less representative. Using a single year of family income rather than a three-year average lowers the estimates of the intergenerational elasticity but has no effect on the changes over time or on the decompositions.

Similarly, restrictions on information regarding both parents' education make little difference to the main estimates on the change in intergenerational mobility. Including fathers' and mothers' education separately also has little effect. In addition, the racial composition of the samples varies across datasets, as is apparent in Table 1. We have rerun all the regressions using just white families and have found virtually identical results.

One further source of reassurance is that our results with the PSID and the early period results using the NLS66 closely match other results in the literature despite differences in sample-selection rules.

\section{Single-Parent Families}

We estimate the main results using two-parent families mainly because of data concerns. For one thing, we would be unable to obtain information on paternal education if we included households headed by single mothers or where no father is present. This omission would make our decomposition analysis 
impossible. A second concern is that families with single mothers are more likely to attrite from long panel surveys such as the NLS and PSID, leading to potentially biased estimates. The income for these families also has more measurement error due to the problem of accounting for all sources of income. ${ }^{26}$

At the same time, focusing only on intact families over a period during which the divorce rate has risen creates a potential sample-selection problem. For example, if income has a greater effect on sons from divorced families, then merely focusing on intact families might understate the true change in the intergenerational elasticity. To investigate this issue, we have rerun the estimates of equation 1 using the same sample-selection rules as before except that sons could now come from households headed by a single parent. We also have eliminated the requirement that years of education be available for the parents.

The results are shown in Table 3. As before, we break down the results for each dataset and for each time period. In the first row, we show the full sample of families that includes single-parent families. In the second row, we show families with both parents present. The results in the second set of rows are different from what is shown in Table 2 because we now include families in which years of parents' education might not be available. The difference in estimates by row is therefore due only to whether or not single-parent families are included.

Starting with the NLS, we find that for all families there is still a rise in the intergenerational elasticity over time, but that it now only increases by .09. The difference, however, is still significant at the 8 percent level. It appears that virtually all of the difference in the change in the elasticity over time between row 1 and row 2 is due to the lower estimate in the later period when using all families. A greater mismeasurement of income for single-parent families might attenuate the coefficient, but it is not clear why this mismeasurement would be greater only in the later period.

Using the PSID, the decline in the elasticity over time is now much less severe than that found using intact families and is no longer statistically significant at any reasonable level. Including all

\footnotetext{
${ }^{26}$ In the earlier survey years, there is often no information collected on the income of unmarried partners or sources of income from other family members.
} 
families substantially changes the estimate for the early period from .452 to .365 , while the estimate for the later period is virtually unchanged. Finally, when including all families in the GSS, the estimate of the change over time sharply increases and is statistically significant at the 1 percent level.

In short, there is no consistent pattern to the effects on the results when including single-parent families. While adding these cases lowers the magnitude of the changes over time in the NLS and PSID, it accentuates the change in the GSS. Overall, results in two of the datasets suggest an increase in the intergenerational elasticity while the third shows no change. We therefore do not believe that the results in Table 3 alter the main conclusion that the inheritability of income appears to have increased over time.

\section{Reconciling the Results with the Literature}

As we noted in the literature review, only a few studies have examined recent changes in the degree of intergenerational income mobility using a single parameter as we have (Hauser, 1998, Fertig, 2001, and Mayer and Lopoo, 2001). Importantly, as noted above, none of these studies has used the NLS cohorts of men that provide significantly larger sample sizes.

One source of difference in our results compared to the earlier literature is the choice of the measure of family income. Hauser, for example, has used occupation-based measures of economic status from the GSS and found no significant changes over time. We find a similar result when using the mean level of income by occupation, industry, class of worker, and region as a proxy for fathers' income. However, when we use the subjective responses of sons' relative family income at age 16 and translate this to a dollar value of income, we find a large change that is close to statistically significant. Although the relative family income measure is very coarse, it does provide one important advantage over the occupation-based measure in that it can be matched more precisely to income during adolescence. The occupation measure, in contrast, can only be matched to the nearest decennial census year. Other arguments certainly may be made as to which is the superior measure; however, short of independent evidence on permanent income, it is difficult to resolve this issue. In any case, while our result with the GSS provides suggestive evidence of an increase in the intergenerational elasticity, alone it is far from 
convincing. However, given the strong result when including single-parent families coupled with the results from the NLS, we believe the balance of the evidence from the GSS supports our conclusion.

A second key difference with our study is that the samples in the NLS are of sufficient size to detect changes over time in the intergenerational elasticity. Both Fertig and Mayer and Lopoo rely exclusively on the small samples available in the PSID. Mayer and Lopoo's methodology is closest to ours in that they define narrow cohorts and look at sons' outcome at a similar age. They also include single-parent households in their samples. As in our study, they do not find a statistically significant decline in the intergenerational elasticity except when they conduct a time-trend analysis that does not include the oldest cohorts in the trend. However, their results from the PSID, like ours, cast some doubt on the robustness of results from the NLS. Ultimately, studies with larger samples are probably needed to fully resolve this question. Perhaps the most promising avenue of future research is to use administrative tax records on large samples of fathers and sons as has been done by Mazumder (2001) for the United States and by Corak and Heisz (1999) for Canada. Once such data for several cohorts of sons are available, this issue may be addressed more convincingly.

\section{Conclusion}

An analysis of three datasets provides some suggestive evidence that the rate of inheritance of economic status rose in recent decades. A comparison of two cohorts from the NLS, which has not been used in previous work on this question, shows a statistically significant increase in the intergenerational elasticity of family income on sons' earnings from 1980 to the early 1990s. In the other two datasets, the change over time is statistically insignificant and of inconsistent signs. When we include single-parent families in our analysis, the increase in the NLS is smaller but still very close to significant, the results from the PSID essentially show no change, and the GSS shows a large and statistically significant increase. At a minimum, we find little or no evidence indicating that the intergenerational elasticity has 
declined, and researchers should be careful not to generalize the results from a small sample in one dataset.

We also decompose the change in the intergenerational elasticity into a channel that operates through sons' education and a channel that is independent of sons' education. Nearly all of the increase in the intergenerational elasticity operates outside the channel of observable human capital. Therefore, if there has been an increase in the rate of inheritance of income, it is for the most part unrelated to any changes in the inheritability of schooling or to the rise in the returns to schooling. This finding is consistent with recent literature indicating that much of the inheritability of income operates outside of the channels that have been traditionally studied by economists. 


\section{References}

Altonji, Joseph G., and Thomas A. Dunn. "Relationships among the Family Incomes and Labor Market Outcomes of Relatives." In Ronald G. Ehrenberg, ed., Research in Labor Economics, Volume 12, . Greenwich, Conn.: JAI Press, 1991, pp. 269-310.

Atkinson, Anthony B. "On Intergenerational Income Mobility in Britain," Journal of Post-Keynesian Economics, Winter 1981, 3, pp. 194-218.

Behrman, Jere R., and Paul Taubman. "Intergenerational Earnings Mobility in the United States: Some Estimates and a Test of Becker's Intergenerational Endowments Model," Review of Economics and Statistics, 67:144-151 1985.

Bowles, Samuel. "Schooling and Inequality from Generation to Generation." Journal of Political Economy 1972, 80: S219-251.

Bowles, Samuel, and Herbert Gintis. "Intergenerational Inequality," forthcoming in Journal of Economic Perspectives, 2001.

Corak, Miles, and Andrew Heisz. "The Intergenerational Earnings and Income Mobility of Canadian Men: Evidence from Longitudinal Income Tax Data." Journal of Human Resources 1999, 34(3):504-533.

Corcoran, Mary; Gordon, Roger; Laren, Deborah; Solon Gary. "The Association Between Men's Economic Status and Their Family and Community Origins." Journal of Human Resources, Fall 1992, 27(4):575-601.

Duncan, Greg J; Boisjoly, Johanne; Smeeding, Timothy. "Economic mobility of young workers in the 1970s and 1980s." Demography, Nov 1996, 33(4):497-509.

Duncan, Greg J., and Jeanne Brooks-Gunn, eds. "Consequences of Growing up Poor.” Russell Sage Foundation, New York, 1997.

Ellwood, David, and Thomas Kane. "Who is Getting a College Education? Family Background and the Growing Gaps in Enrollment." Mimeo, Harvard Kennedy School of Government, 1999.

Fertig, Angela R. "Trends in Intergenerational Mobility." Center for Research on Child Wellbeing. Working Paper \#01-23, Princeton University 2001.

Goldberger, Arthur. "Economic and Mechanical Models of Intergenerational Transmission." American Economic Review, June 1989, 79, 504-13.

Gottschalk, Peter, Sara McLanahan, and Gary D. Sandefur. "The Dynammics and Intergenerational Transmission of Poverty and Welfare Participation," in Sheldon Danzinger, Gary Sandefur, and Daniel Weinberg, eds., Confronting Poverty, Harvard, Cambridge: MA, 1994, pp. 85108 .

Gottschalk, Peter, and Robert A. Moffitt, "The Growth of Earnings Instability in the U.S. Labor Market." Brookings Papers on Economic Activity 1994, 2:217-272.

Hauser, Robert M. "Intergenerational Economic Mobility in the United States Measures, Differentials, and Trends." Manuscript, University of Wisconsin, 1998.

Hauser, Robert M.,and David L. Featherman. The Process of Stratification: Trends and Analyses, NY, Academic, 1977.

Hout, Michael, "More Universalism, Less Structural Mobility: The American Occupational Structure in the 1980's," American Journal of Sociology, 9, May, 1988, 1358-1400. 
Institute for Social Research, University of Michigan, "An Overview of the Panel Study of Income Dynamics," 2000 [http://www.isr.umich.edu/src/psid/overview.html].

Kane, Thomas, and Ellwood, Davis. "Who is Getting a College Education? Family Background and the Growing Gaps in Enrollment," Mimeo, Kennedy School of Government, 1999.

Levy, Frank; and Murnane, Richard J. "U.S. Earnings Levels and Earnings Inequality: A Review of Recent Trends and Proposed Explanations.” Journal of Economic Literature, Sep. 1992, 30(3):1333-1381.

Manski, Charles. "Income and Higher Eduation," Focus, University of Wisconsin-Madison, Institute for Research on Poverty, 13, 3, Winter 1992-93: 14-19.

Massagli, Michael P., and Hauser, Robert M. "Response Variability in Self- and Proxy Reports of Paternal and Filial Socioeconomic Characteristics." American Journal of Sociology, September 1983, 89, pp. 420-31.

Mayer, Susan. “What Money Can’t Buy: Family Income and Children's Life Chances.” Harvard University Press, Cambridge Mass., 1997.

Mayer, Susan E., and Lopoo, Leonard M. "Has the Intergenerational Transmission of Economic Status Changed?" Manuscript, 2001

McMurrer, Daniel P., Mark Condon, and Isabel V. Sawhill. "Intergenerational Mobility In the United States," Urban Institute, May 1997 [http://www.urban.org/oppor/opp_04b.htm].

Mazumder, Bhashkar. "Earnings Mobility in the US: A New Look at Intergenerational Inequality." Federal Reserve Bank of Chicago Working Paper, 2001-18, 2001.

Menchik, Paul L. "Intergenerational Transmission of Inequality: An Empirical Study of Wealth Mobility," Economica 46:349-363, 1979.

Mulligan, Casey B. Parental Priorities and Economic Inequality. University of Chicago Press, Chicago, 1997.

Murphy, Kevin M., and Finis Welch. "The Structure of Wages." Quarterly Journal of Economics, Feb. 1992, 107(1):285-326.

Osbourne, Melissa A. "Personality And The Intergenerational Transmission Of Earnings." Manuscript, Towson State, MD. 2001.

Peters, H. Elizabeth. Patterns of Intergenerational Mobility in Income and Earnings. Review of Economics \& Statistics, Aug 1992, 74(3):456-466.

Sewell, William H., and Robert M. Hauser. Education, Occupation and Earnings: Achievements in the Early Career. Academic Press, New York, 1975.

Shea, John. “Does Parents' Money Matter.” Journal of Public Economics, 2000, 77(2):155-184.

Solon, Gary. "Biases in the Estimation of Intergenerational Earnings Correlations." Review of Economics and Statistics, 1989 71:172-174.

Solon, Gary. "Intergenerational Income Mobility in the United States." American Economic Review, June 1992, 82, 3, pp. 393-408.

Solon, Gary. "Intergenerational Mobility in the Labor Market," Handbook of Labor Economics, Elsevier, 1999

Zimmerman, David J. "A Regression Toward Mediocrity in Economic Stature." American Economic Review, June 1992, 82, 3, pp. 409-429. 
Table 1: Summary Statistics

\begin{tabular}{|c|c|c|c|c|}
\hline \multirow[t]{2}{*}{ NLS } & \multicolumn{2}{|c|}{$\begin{array}{l}1980 \text { analysis } \\
\text { (NLS66) }\end{array}$} & \multicolumn{2}{|c|}{$\begin{array}{l}1993 \text { analysis } \\
\text { (NLSY79) }\end{array}$} \\
\hline & Mean & S.D. & Mean & S.D. \\
\hline Log son's annual earnings (1966 or 1978 dollars) & 8.62 & 0.65 & 9.32 & 0.81 \\
\hline Son's age & 31.17 & 2.00 & 31.02 & 2.10 \\
\hline Son is Black & 0.17 & 0.38 & 0.23 & 0.42 \\
\hline Son's years of education & 13.91 & 2.51 & 13.35 & 2.33 \\
\hline Log avg. family income (1966-68 or 1978-80) & 9.08 & 0.63 & 9.74 & 0.63 \\
\hline Parents' years of education & 21.22 & 6.23 & 23.46 & 5.22 \\
\hline \multicolumn{5}{|l|}{ PSID } \\
\hline & \multicolumn{2}{|c|}{1980 analysis } & \multicolumn{2}{|c|}{1992 analysis } \\
\hline Log son's annual earnings (1967 or 1978 dollars) & 8.67 & 0.72 & 9.30 & 0.92 \\
\hline Son's age & 28.75 & 1.39 & 30.71 & 2.35 \\
\hline Son is Black & 0.27 & 0.44 & 0.27 & 0.44 \\
\hline Son's years of education & 13.11 & 2.19 & 13.41 & 2.07 \\
\hline Log avg. family income (1967-69 or 1978-80) & 9.07 & 0.61 & 10.07 & 0.56 \\
\hline Parents' years of education & 20.09 & 6.52 & 23.11 & 5.56 \\
\hline GSS & \multicolumn{2}{|c|}{$1976-1984$ analysis } & \multicolumn{2}{|c|}{ 1989-1994 analysis } \\
\hline Log son's annual earnings (1997 dollars) & 10.33 & 0.77 & 10.32 & 0.70 \\
\hline Son's age & 31.92 & 2.56 & 32.28 & 2.63 \\
\hline Son is Black & 0.09 & 0.28 & 0.06 & 0.23 \\
\hline Son's years of education & 13.77 & 2.79 & 13.81 & 2.63 \\
\hline Log Family Income at 16 (1997 dollars) & 10.25 & 0.22 & 10.53 & 0.17 \\
\hline Parents' years of education & 19.70 & 8.86 & 22.18 & 8.97 \\
\hline
\end{tabular}

Note: The summary statistics are shown for the samples used in the estimates for Table 2. The summary statistics for the GSS refer to the samples when using the relative family income variable. See the text for specific information as to how the samples are constructed. 
Table 2: Decomposing changes in the intergenerational elasticity over time

\begin{tabular}{|c|c|c|c|c|c|c|c|}
\hline \multirow{3}{*}{$\begin{array}{l}\text { Panel A: NLS } \\
\text { Equation } 1: \\
y_{s}=\rho^{*} y_{f}+w\end{array}$} & \multirow[b]{3}{*}{$\begin{array}{l}\rho^{*} \\
R \text { squared }\end{array}$} & \multicolumn{2}{|c|}{1980 (NLS66) } & \multicolumn{2}{|c|}{1993 (NLSY79) } & \multirow{2}{*}{\multicolumn{2}{|c|}{$\begin{array}{l}\text { Coefficient } \\
\text { Change } \\
\text { Over Time t-stat }\end{array}$}} \\
\hline & & coeff. & s.e & coeff. & s.e & & \\
\hline & & $\begin{array}{l}0.217 \\
0.039\end{array}$ & $\overline{(0.042)}$ & $\begin{array}{l}0.414 \\
0.090\end{array}$ & $\overline{(0.050)}$ & 0.197 & 3.013 \\
\hline $\begin{array}{l}\text { Equation 2: } \\
\mathrm{y}_{\mathrm{s}}=\beta \mathrm{e}_{\mathrm{s}}+\gamma \mathrm{e}_{\mathrm{f}}+\rho \mathrm{y}_{\mathrm{f}}+\varepsilon\end{array}$ & $\begin{array}{c}\beta \\
\gamma \\
\rho \\
\text { R squared }\end{array}$ & $\begin{array}{l}0.050 \\
0.000 \\
0.137 \\
0.069\end{array}$ & $\begin{array}{l}(0.010) \\
(0.005) \\
(0.051)\end{array}$ & $\begin{array}{l}0.097 \\
0.001 \\
0.319 \\
0.162\end{array}$ & $\begin{array}{l}(0.011) \\
(0.006) \\
(0.054)\end{array}$ & $\begin{array}{l}0.047 \\
0.000 \\
0.182\end{array}$ & $\begin{array}{l}3.169 \\
0.034 \\
2.447\end{array}$ \\
\hline $\begin{array}{l}\text { Equation 3: } \\
\mathrm{e}_{\mathrm{s}}=\tau \mathrm{e}_{\mathrm{f}}+\lambda \mathrm{y}_{\mathrm{f}}+\mathrm{u}\end{array}$ & $\begin{array}{c}\lambda \\
\tau \\
\text { R squared }\end{array}$ & $\begin{array}{l}0.748 \\
0.150 \\
0.245\end{array}$ & $\begin{array}{l}(0.145) \\
(0.015)\end{array}$ & $\begin{array}{l}0.421 \\
0.181 \\
0.193\end{array}$ & $\begin{array}{l}(0.118) \\
(0.014)\end{array}$ & $\begin{array}{r}-0.327 \\
0.031\end{array}$ & $\begin{array}{r}-1.748 \\
1.474\end{array}$ \\
\hline $\begin{array}{l}\text { Equation 4: } \\
\mathrm{e}_{\mathrm{f}}=\delta \mathrm{y}_{\mathrm{f}}+\mathrm{v}\end{array}$ & $\begin{array}{l}\delta \\
R \text { squared } \\
N=\end{array}$ & $\begin{array}{r}5.470 \\
0.287 \\
868\end{array}$ & $(0.336)$ & $\begin{array}{r}2.981 \\
0.127 \\
1082\end{array}$ & $(0.257)$ & -2.489 & -5.892 \\
\hline $\begin{array}{l}\text { Decomposition } \\
\text { Change in Intergenerationa } \\
\text { Portion due to son's educat } \\
\text { Portion not due to son's ed }\end{array}$ & $\begin{array}{l}\text { Elasticity } \\
\text { ion } \\
\text { ucation }\end{array}$ & $\begin{array}{l}0.197 \\
0.015 \\
0.183\end{array}$ & & & & & \\
\hline
\end{tabular}

Panel B: PSID

Equation 1:

$\mathrm{y}_{\mathrm{s}}=\rho^{*} \mathrm{y}_{\mathrm{f}}+\mathrm{w}$

Equation 2:

$\mathrm{y}_{\mathrm{s}}=\beta \mathrm{e}_{\mathrm{s}}+\gamma \mathrm{e}_{\mathrm{f}}+\rho \mathrm{y}_{\mathrm{f}}+\varepsilon \quad \rho$

$\mathrm{R}$ squared

Equation 3:

$\mathrm{e}_{\mathrm{s}}=\tau \mathrm{e}_{\mathrm{f}}+\lambda \mathrm{y}_{\mathrm{f}}+\mathrm{u}$

$\lambda$

$\tau$

R squared

0.521

0.151

0.271

$(0.250)$

$(0.021)$

$6.515 \quad(0.672)$

Equation 4:

$\mathrm{e}_{\mathrm{f}}=\delta \mathrm{y}_{\mathrm{f}}+\mathrm{v}$
$(0.020)$

$(0.008)$

$(0.112)$

0.173

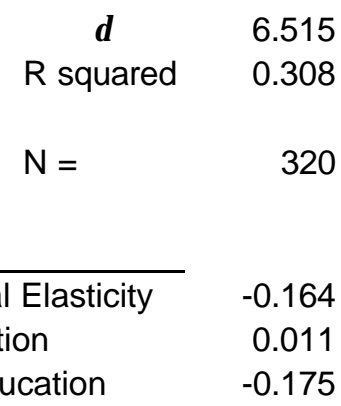

1992

\begin{tabular}{|c|c|c|c|}
\hline coeff. & s.e & change & t-stat \\
\hline 0.288 & $(0.066)$ & -0.164 & -1.352 \\
\hline \multicolumn{4}{|l|}{0.038} \\
\hline 0.098 & $(0.025)$ & 0.022 & 0.685 \\
\hline 0.021 & (0.009) & 0.019 & 1.562 \\
\hline 0.034 & $(0.073)$ & -0.285 & -2.129 \\
\hline \multicolumn{4}{|l|}{0.138} \\
\hline 0.274 & $(0.188)$ & -0.248 & -0.791 \\
\hline 0.170 & $(0.019)$ & 0.019 & 0.655 \\
\hline 0.266 & & & \\
\hline
\end{tabular}

$\begin{array}{llll}5.967 & (0.584) & -0.548 & -0.615\end{array}$

464

Decomposition

\begin{tabular}{lrr}
\hline Change in Intergenerational Elasticity & -0.164 \\
Portion due to son's education & 0.011 \\
Portion not due to son's education & -0.175
\end{tabular}


Table 2: Decomposing changes in the intergenerational elasticity over time, cont.

Panel C:

GSS Using Relative Family Income

1976-1984

1989-1994

Equation 1:

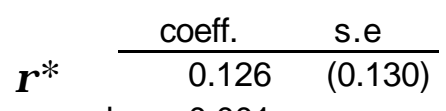

$y_{s}=\rho^{*} y_{f}+w$

$R$ squared

0.001

\begin{tabular}{cc} 
coeff. & s.e \\
\hline 0.513 & $(0.180)$
\end{tabular}

$\frac{\text { change t-stat }}{0.386 \quad 1.743}$

$\begin{array}{lcrr}\text { Equation 2: } & \beta & 0.047 & (0.012) \\ \mathrm{y}_{\mathrm{s}}=\beta \mathrm{e}_{\mathrm{s}}+\gamma \mathrm{e}_{\mathrm{f}}+\rho \mathrm{y}_{\mathrm{f}}+\varepsilon & \gamma & 0.010 & (0.005) \\ & \rho & -0.127 & (0.137)\end{array}$

$\mathrm{R}$ squared $\quad 0.047$

0.016

$\begin{array}{rrrr}0.099 & (0.012) & 0.052 & 3.069 \\ -0.001 & (0.005) & -0.011 & -1.758 \\ 0.275 & (0.175) & 0.403 & 1.809 \\ 0.150 & & & \end{array}$

Equation 3:

$\mathrm{e}_{\mathrm{s}}=\tau \mathrm{e}_{\mathrm{f}}+\lambda \mathrm{y}_{\mathrm{f}}+\mathrm{u}$

$\begin{array}{lll}\lambda & 0.318 & (0.443)\end{array}$

0.449

$(0.636)$

0.130

0.168

$\tau$

$0.175 \quad(0.013)$

0.166

(0.015)

$-0.009$

$-0.440$

R squared $\quad 0.246$

0.225

Equation 4:

$\mathrm{e}_{\mathrm{f}}=\delta \mathrm{y}_{\mathrm{f}}+\mathrm{v}$

$\begin{array}{cr}\delta & 12.947 \\ \text { R squared } & 0.146\end{array}$

(1.181)

12.714

$(1.845)$

$-0.233$

$-0.106$

0.088

$N=$

706

497

Decomposition

Change in Intergenerational Elasticity
Portion due to son's education
Portion not due to son's education
Panel D:
GSS Using Occupational Income

0.386

0.130

0.256

Equation 1:

$\mathrm{y}_{\mathrm{s}}=\rho^{*} \mathrm{y}_{\mathrm{f}}+\mathrm{w}$

$\begin{array}{lccc}\text { Equation 2: } & \beta & 0.047 & (0.012) \\ \mathrm{y}_{\mathrm{s}}=\beta \mathrm{e}_{\mathrm{s}}+\gamma \mathrm{e}_{\mathrm{f}}+\rho \mathrm{y}_{\mathrm{f}}+\varepsilon & \gamma & 0.008 & (0.005) \\ & \rho & 0.020 & (0.071)\end{array}$

Equation 3:

$\mathrm{e}_{\mathrm{s}}=\tau \mathrm{e}_{\mathrm{f}}+\lambda \mathrm{y}_{\mathrm{f}}+\mathrm{u}$

$\begin{array}{lll}\lambda & 0.796 & (0.226) \\ \tau & 0.159 & (0.014)\end{array}$

$\mathrm{R}$ squared

Equation 4:

$\mathrm{e}_{\mathrm{f}}=\delta \mathrm{y}_{\mathrm{f}}+\mathrm{v}$ $\begin{array}{lll}\delta & 7.971 \quad(0.542)\end{array}$

R squared

$N=$

0.237

698
$0.159 \quad(0.014)$

0.259

1976-1984

coeff.

$0.178 \quad(0.063)$

0.011
1989-1994

\begin{tabular}{|c|c|c|c|}
\hline coeff. & s.e & change & t-stat \\
\hline 0.192 & $(0.075)$ & 0.014 & 0.145 \\
\hline 0.013 & & & \\
\hline 0.103 & $(0.013)$ & 0.057 & 3.275 \\
\hline 0.001 & (0.005) & -0.007 & -0.998 \\
\hline-0.013 & $(0.079)$ & -0.033 & -0.314 \\
\hline 0.156 & & & \\
\hline
\end{tabular}

$\begin{array}{llll}0.657 & (0.280) & -0.140 & -0.388\end{array}$

$\begin{array}{llll}0.163 & (0.016) & 0.004 & 0.189\end{array}$

0.249

$7.728 \quad(0.699)$

$-0.243$

$-0.274$

0.202

485

Decomposition

Change in Intergenerational Elasticity

Portion due to son's education

Portion not due to son's education

$-0.088$ 
Table 3: Results when including single parent families

\begin{tabular}{|c|c|c|c|c|}
\hline NLS & $\begin{array}{c}\text { (NLS66) } \\
1980 \\
\text { coeff. } \\
\end{array}$ & $\begin{array}{c}\text { (NLSY79) } \\
1993 \\
\text { coeff. } \\
\end{array}$ & $\begin{array}{l}\text { Coefficient } \\
\text { Change } \\
\text { Over Time }\end{array}$ & \\
\hline All Families & $\begin{array}{r}0.235 \\
(0.033) \\
1100\end{array}$ & $\begin{array}{r}0.330 \\
(0.043) \\
1459\end{array}$ & 0.094 & 1.739 \\
\hline Two Parents Families & $\begin{array}{r}0.229 \\
(0.035) \\
1050\end{array}$ & $\begin{array}{r}0.391 \\
(0.045) \\
1227\end{array}$ & 0.162 & 2.841 \\
\hline $\begin{array}{l}\text { Coefficient Difference } \\
\text { t-stat }\end{array}$ & $\begin{array}{l}-0.006 \\
-0.127 \\
\end{array}$ & $\begin{array}{l}0.061 \\
0.984 \\
\end{array}$ & & \\
\hline \multicolumn{5}{|l|}{ PSID } \\
\hline All Families & $\begin{array}{r}0.365 \\
(0.073) \\
432\end{array}$ & $\begin{array}{r}0.286 \\
(0.060) \\
616\end{array}$ & -0.079 & -0.834 \\
\hline Two Parents Families & $\begin{array}{r}0.452 \\
(0.102) \\
321\end{array}$ & $\begin{array}{r}0.289 \\
(0.065) \\
472\end{array}$ & -0.163 & -1.352 \\
\hline $\begin{array}{l}\text { Coefficient Difference } \\
\text { t-stat }\end{array}$ & $\begin{array}{l}0.087 \\
0.694\end{array}$ & $\begin{array}{l}0.002 \\
0.028\end{array}$ & & \\
\hline
\end{tabular}

GSS using Relative Family Income

\begin{tabular}{lrrrr} 
All Families & 0.168 & 0.662 & 0.494 & 2.527 \\
& $(0.118)$ & $(0.156)$ & & \\
& 811 & 598 & & \\
Two Parents Families & 0.115 & 0.491 & 0.376 & 1.724 \\
& $(0.129)$ & $(0.176)$ & & \\
& 724 & 512 & & \\
Coefficient Difference & & & & \\
t-stat & -0.053 & -0.171 & \\
\hline
\end{tabular}

Note: In all three datasets the sample selection rules are the same as in Table 2 (see text) except that observations with missing values for parent education are included and families are not required to have both parents present in the home during adolescence. 


\section{Working Paper Series}

A series of research studies on regional economic issues relating to the Seventh Federal Reserve District, and on financial and economic topics.

Extracting Market Expectations from Option Prices:

WP-99-1

Case Studies in Japanese Option Markets

Hisashi Nakamura and Shigenori Shiratsuka

Measurement Errors in Japanese Consumer Price Index

WP-99-2

Shigenori Shiratsuka

Taylor Rules in a Limited Participation Model

WP-99-3

Lawrence J. Christiano and Christopher J. Gust

Maximum Likelihood in the Frequency Domain: A Time to Build Example

WP-99-4

Lawrence J.Christiano and Robert J. Vigfusson

Unskilled Workers in an Economy with Skill-Biased Technology

WP-99-5

Shouyong Shi

Product Mix and Earnings Volatility at Commercial Banks:

WP-99-6

Evidence from a Degree of Leverage Model

Robert DeYoung and Karin P. Roland

School Choice Through Relocation: Evidence from the Washington D.C. Area

WP-99-7

Lisa Barrow

Banking Market Structure, Financial Dependence and Growth:

International Evidence from Industry Data

WP-99-8

Nicola Cetorelli and Michele Gambera

Asset Price Fluctuation and Price Indices

WP-99-9

Shigenori Shiratsuka

Labor Market Policies in an Equilibrium Search Model

WP-99-10

Fernando Alvarez and Marcelo Veracierto

Hedging and Financial Fragility in Fixed Exchange Rate Regimes

WP-99-11

Craig Burnside, Martin Eichenbaum and Sergio Rebelo

Banking and Currency Crises and Systemic Risk: A Taxonomy and Review

WP-99-12

George G. Kaufman

Wealth Inequality, Intergenerational Links and Estate Taxation

WP-99-13

Mariacristina De Nardi

Habit Persistence, Asset Returns and the Business Cycle

WP-99-14

Michele Boldrin, Lawrence J. Christiano, and Jonas D.M Fisher

Does Commodity Money Eliminate the Indeterminacy of Equilibria?

WP-99-15 Ruilin Zhou

A Theory of Merchant Credit Card Acceptance

WP-99-16 Sujit Chakravorti and Ted To 


\section{Working Paper Series (continued)}

Who's Minding the Store? Motivating and Monitoring Hired Managers at

WP-99-17 Small, Closely Held Firms: The Case of Commercial Banks

Robert DeYoung, Kenneth Spong and Richard J. Sullivan

Assessing the Effects of Fiscal Shocks

WP-99-18

Craig Burnside, Martin Eichenbaum and Jonas D.M. Fisher

Fiscal Shocks in an Efficiency Wage Model

WP-99-19

Craig Burnside, Martin Eichenbaum and Jonas D.M. Fisher

Thoughts on Financial Derivatives, Systematic Risk, and Central

WP-99-20

Banking: A Review of Some Recent Developments

William C. Hunter and David Marshall

Testing the Stability of Implied Probability Density Functions

WP-99-21

Robert R. Bliss and Nikolaos Panigirtzoglou

Is There Evidence of the New Economy in the Data?

WP-99-22

Michael A. Kouparitsas

A Note on the Benefits of Homeownership

WP-99-23

Daniel Aaronson

The Earned Income Credit and Durable Goods Purchases

WP-99-24

Lisa Barrow and Leslie McGranahan

Globalization of Financial Institutions: Evidence from Cross-Border

WP-99-25

Banking Performance

Allen N. Berger, Robert DeYoung, Hesna Genay and Gregory F. Udell

Intrinsic Bubbles: The Case of Stock Prices A Comment

WP-99-26

Lucy F. Ackert and William C. Hunter

Deregulation and Efficiency: The Case of Private Korean Banks

WP-99-27

Jonathan Hao, William C. Hunter and Won Keun Yang

Measures of Program Performance and the Training Choices of Displaced Workers

WP-99-28

Louis Jacobson, Robert LaLonde and Daniel Sullivan

The Value of Relationships Between Small Firms and Their Lenders

WP-99-29

Paula R. Worthington

Worker Insecurity and Aggregate Wage Growth

WP-99-30

Daniel Aaronson and Daniel G. Sullivan

Does The Japanese Stock Market Price Bank Risk? Evidence from Financial

WP-99-31

Firm Failures

Elijah Brewer III, Hesna Genay, William Curt Hunter and George G. Kaufman

Bank Competition and Regulatory Reform: The Case of the Italian Banking Industry

WP-99-32

Paolo Angelini and Nicola Cetorelli 


\section{Working Paper Series (continued)}

Dynamic Monetary Equilibrium in a Random-Matching Economy

WP-00-1

Edward J. Green and Ruilin Zhou

The Effects of Health, Wealth, and Wages on Labor Supply and Retirement Behavior

WP-00-2

Eric French

Market Discipline in the Governance of U.S. Bank Holding Companies:

WP-00-3

Monitoring vs. Influencing

Robert R. Bliss and Mark J. Flannery

Using Market Valuation to Assess the Importance and Efficiency

of Public School Spending

WP-00-4

Lisa Barrow and Cecilia Elena Rouse

Employment Flows, Capital Mobility, and Policy Analysis

WP-00-5

Marcelo Veracierto

Does the Community Reinvestment Act Influence Lending? An Analysis

of Changes in Bank Low-Income Mortgage Activity

WP-00-6

Drew Dahl, Douglas D. Evanoff and Michael F. Spivey

Subordinated Debt and Bank Capital Reform

WP-00-7

Douglas D. Evanoff and Larry D. Wall

The Labor Supply Response To (Mismeasured But) Predictable Wage Changes

WP-00-8

Eric French

For How Long Are Newly Chartered Banks Financially Fragile?

WP-00-9

Robert DeYoung

Bank Capital Regulation With and Without State-Contingent Penalties

David A. Marshall and Edward S. Prescott

WP-00-10

Why Is Productivity Procyclical? Why Do We Care?

WP-00-11

Susanto Basu and John Fernald

Oligopoly Banking and Capital Accumulation

WP-00-12

Nicola Cetorelli and Pietro F. Peretto

Puzzles in the Chinese Stock Market

WP-00-13

John Fernald and John H. Rogers

The Effects of Geographic Expansion on Bank Efficiency

WP-00-14

Allen N. Berger and Robert DeYoung

Idiosyncratic Risk and Aggregate Employment Dynamics

WP-00-15

Jeffrey R. Campbell and Jonas D.M. Fisher

Post-Resolution Treatment of Depositors at Failed Banks: Implications for the Severity of Banking Crises, Systemic Risk, and Too-Big-To-Fail

WP-00-16 George G. Kaufman and Steven A. Seelig 


\section{Working Paper Series (continued)}

The Double Play: Simultaneous Speculative Attacks on Currency and Equity Markets

WP-00-17

Sujit Chakravorti and Subir Lall

Capital Requirements and Competition in the Banking Industry

WP-00-18

Peter J.G. Vlaar

Financial-Intermediation Regime and Efficiency in a Boyd-Prescott Economy

WP-00-19

Yeong-Yuh Chiang and Edward J. Green

How Do Retail Prices React to Minimum Wage Increases?

WP-00-20

James M. MacDonald and Daniel Aaronson

Financial Signal Processing: A Self Calibrating Model

WP-00-21

Robert J. Elliott, William C. Hunter and Barbara M. Jamieson

An Empirical Examination of the Price-Dividend Relation with Dividend Management

WP-00-22

Lucy F. Ackert and William C. Hunter

Savings of Young Parents

Annamaria Lusardi, Ricardo Cossa, and Erin L. Krupka

The Pitfalls in Inferring Risk from Financial Market Data

Robert R. Bliss

What Can Account for Fluctuations in the Terms of Trade?

WP-00-25

Marianne Baxter and Michael A. Kouparitsas

Data Revisions and the Identification of Monetary Policy Shocks

WP-00-26

Dean Croushore and Charles L. Evans

Recent Evidence on the Relationship Between Unemployment and Wage Growth

WP-00-27

Daniel Aaronson and Daniel Sullivan

Supplier Relationships and Small Business Use of Trade Credit

WP-00-28

Daniel Aaronson, Raphael Bostic, Paul Huck and Robert Townsend

What are the Short-Run Effects of Increasing Labor Market Flexibility?

WP-00-29

Marcelo Veracierto

Equilibrium Lending Mechanism and Aggregate Activity

WP-00-30

Cheng Wang and Ruilin Zhou

Impact of Independent Directors and the Regulatory Environment on Bank Merger Prices:

Evidence from Takeover Activity in the 1990s

Elijah Brewer III, William E. Jackson III, and Julapa A. Jagtiani

WP-00-31

Does Bank Concentration Lead to Concentration in Industrial Sectors?

WP-01-01

Nicola Cetorelli

On the Fiscal Implications of Twin Crises

WP-01-02

Craig Burnside, Martin Eichenbaum and Sergio Rebelo 


\section{Working Paper Series (continued)}

Sub-Debt Yield Spreads as Bank Risk Measures

WP-01-03

Douglas D. Evanoff and Larry D. Wall

Productivity Growth in the 1990s: Technology, Utilization, or Adjustment?

WP-01-04

Susanto Basu, John G. Fernald and Matthew D. Shapiro

Do Regulators Search for the Quiet Life? The Relationship Between Regulators and

The Regulated in Banking

Richard J. Rosen

WP-01-05

Learning-by-Doing, Scale Efficiencies, and Financial Performance at Internet-Only Banks

WP-01-06

Robert DeYoung

The Role of Real Wages, Productivity, and Fiscal Policy in Germany's

Great Depression 1928-37

WP-01-07

Jonas D. M. Fisher and Andreas Hornstein

Nominal Rigidities and the Dynamic Effects of a Shock to Monetary Policy

WP-01-08

Lawrence J. Christiano, Martin Eichenbaum and Charles L. Evans

Outsourcing Business Service and the Scope of Local Markets

WP-01-09

Yukako Ono

The Effect of Market Size Structure on Competition: The Case of Small Business Lending

WP-01-10 Allen N. Berger, Richard J. Rosen and Gregory F. Udell

Deregulation, the Internet, and the Competitive Viability of Large Banks and Community Banks WP-01-11 Robert DeYoung and William C. Hunter

Price Ceilings as Focal Points for Tacit Collusion: Evidence from Credit Cards

WP-01-12

Christopher R. Knittel and Victor Stango

Gaps and Triangles

WP-01-13

Bernardino Adão, Isabel Correia and Pedro Teles

A Real Explanation for Heterogeneous Investment Dynamics

WP-01-14

Jonas D.M. Fisher

Recovering Risk Aversion from Options

WP-01-15

Robert R. Bliss and Nikolaos Panigirtzoglou

Economic Determinants of the Nominal Treasury Yield Curve

WP-01-16

Charles L. Evans and David Marshall

Price Level Uniformity in a Random Matching Model with Perfectly Patient Traders

WP-01-17

Edward J. Green and Ruilin Zhou

Earnings Mobility in the US: A New Look at Intergenerational Inequality

WP-01-18

Bhashkar Mazumder

The Effects of Health Insurance and Self-Insurance on Retirement Behavior

WP-01-19

Eric French and John Bailey Jones 


\section{Working Paper Series (continued)}

The Effect of Part-Time Work on Wages: Evidence from the Social Security Rules

WP-01-20

Daniel Aaronson and Eric French

Antidumping Policy Under Imperfect Competition

WP-01-21

Meredith A. Crowley

Is the United States an Optimum Currency Area?

An Empirical Analysis of Regional Business Cycles

WP-01-22

Michael A. Kouparitsas

A Note on the Estimation of Linear Regression Models with Heteroskedastic

Measurement Errors

WP-01-23

Daniel G. Sullivan

The Mis-Measurement of Permanent Earnings: New Evidence from Social

Security Earnings Data

Bhashkar Mazumder

Pricing IPOs of Mutual Thrift Conversions: The Joint Effect of Regulation and Market Discipline

Elijah Brewer III, Douglas D. Evanoff and Jacky So

WP-01-25

Opportunity Cost and Prudentiality: An Analysis of Collateral Decisions in Bilateral and Multilateral Settings

Herbert L. Baer, Virginia G. France and James T. Moser

WP-01-26

Outsourcing Business Services and the Role of Central Administrative Offices

WP-02-01

Yukako Ono

Strategic Responses to Regulatory Threat in the Credit Card Market*

WP-02-02

Victor Stango

The Optimal Mix of Taxes on Money, Consumption and Income

WP-02-03

Fiorella De Fiore and Pedro Teles

Expectation Traps and Monetary Policy

Stefania Albanesi, V. V. Chari and Lawrence J. Christiano

WP-02-04

Monetary Policy in a Financial Crisis

WP-02-05

Lawrence J. Christiano, Christopher Gust and Jorge Roldos

Regulatory Incentives and Consolidation: The Case of Commercial Bank Mergers and the Community Reinvestment Act

Raphael Bostic, Hamid Mehran, Anna Paulson and Marc Saidenberg

WP-02-06

Technological Progress and the Geographic Expansion of the Banking Industry

WP-02-07

Allen N. Berger and Robert DeYoung

Choosing the Right Parents: Changes in the Intergenerational Transmission

WP-02-08

of Inequality — Between 1980 and the Early 1990s

David I. Levine and Bhashkar Mazumder 